Jose Z. Fernando III, MD

Rosario R. Ricalde, MD

Department of Otorhinolaryngology

Head and Neck Surgery

Quirino Memorial Medical Center
Correspondence: Dr. Rosario R. Ricalde Department of Otorhinolaryngology Head and Neck Surgery

Quirino Memorial Medical Center

Katipunan Road Ext., Project 4, Quezon City 1108

Philippines

Phone: (632) 4212250 local 117

Email: quirino_orlhns@yahoo.com

The authors declared that this represents original material that is not being considered for publication or has not been published or accepted for publication elsewhere in full or in part, in print or electronic media; that the manuscript has been read and approved by all the authors, that the requirements for authorship have been met by each author, and that each author believes that the manuscript represents honest work.

Disclosures: The authors signed disclosures that there are no financial or other (including personal) relationships, intellectual passion, political or religious beliefs, and institutional affiliations that might lead to a conflict of interest.

Presented at the Philippine Society of Otolaryngology-Head and Neck Surgery, Interesting Case Contest. June 2, 2015. Menarini Office, 4/FW Building, BGC Taguig City.

\section{Capillary Hemangioma of the Temporal Bone}

\begin{abstract}
Objectives: To discuss a rare case of temporal bone capillary hemangioma and its diagnosis and
\end{abstract} management.

\section{Methods:}

$\begin{array}{ll}\text { Design: } & \text { Case Report } \\ \text { Setting: } & \text { Tertiary Government Hospital } \\ \text { Patient: } & \text { One }\end{array}$

Results: A 44-year-old woman with a history of on-and-off right ear discharge, tinnitus and decreased hearing, and a pinkish, smooth-surfaced, non-friable, non-pulsating mass occluding the right external auditory canal, was initially treated for chronic suppurative otitis media with aural polyp. A punch biopsy due to persistence of disease despite medical treatment revealed capillary hemangioma. She underwent canal wall down mastoidectomy with obliteration to completely resect the tumor.

Conclusion: Capillary hemangiomas of the temporal bone are benign lesions that may lead to complications such as bone erosion, hearing loss, recurrent infection and bleeding if left untreated. Surgery remains the ideal treatment and recurrence is rare and the prognosis is good if resection is complete.

Keywords: Hemangioma, capillary hemangioma, temporal bone, middle ear

Hemangiomas in the head and neck are common accounting for more than 60 percent of all hemangiomas. ${ }^{1}$ They are vascular anomalies commonly seen in children and young adults that usually grow intermittently throughout the first year of life, go through a quiescent period then spontaneously involute by 5 or 6 years old. ${ }^{1}$ They are exceptionally reported in the middle ear. ' When located in the temporal bone they are commonly seen in adults such as in this case. This case was initially treated as a case of chronic supportive otitis media with aural polyp, a protracted treatment period that may have led to progression of the disease and complications. 
The majority of intraosseous hemangiomas arising from the skull base are cavernous and only few are capillary. ${ }^{2}$ Capillary hemangiomas arise predominantly in the area of the geniculate ganglion and the internal auditory canal. ${ }^{2,3}$ According to Singh et al., only 18 cases have been reported in English literature, with 8 cases confined to the middle ear and 9 cases confined to the external auditory canal, plus a case with involvement of the mastoid, middle ear and external ear canal. ${ }^{4}$ The patient was initially diagnosed as chronic suppurative otitis media with aural polyp until biopsy and subsequent surgery discredited the initial diagnosis with an impression of capillary hemangioma. We present a similar case.

\section{CASE REPORT}

A 44-year-old woman presented with a history of on-and-off right ear discharge of 8 years duration. She also noted tinnitus and decreased hearing after 3 years and reported right aural bleeding and postauricular swelling and discharge. No facial asymmetry was observed. She was treated for chronic suppurative otitis media with aural polyp without relief.

The patient was seen 8 years after the onset of symptoms. On examination, a pinkish, smooth-surfaced, non-friable, non-pulsating mass occluded the right external auditory canal. A draining postauricular sinus was surrounded by a hypertrophic scar. (Figure 1)

Temporal bone computed tomography showed a heterogenous mass with enhancement in the right external ear canal with canal erosions extending to the right temporo-mandibular joint and space behind the right parotid gland. (Figure 2) Pure Tone Audiometry revealed conductive hearing loss on the right. A punch biopsy revealed capillary hemangioma. Mild bleeding was observed during the biopsy, easily controlled by packing.

The patient underwent canal wall down mastoidectomy with mastoid obliteration using abdominal fat and temporalis muscle and blind sac closure. Intra-operatively, a friable mass surrounded by granulation tissue occupied the epitympanum, middle ear cavity and external auditory canal eroding the mallues, incus and stapes suprastructure. The stapes foot plate was fixed. (Figure 3) Histopathology showed proliferation of well-circumscribed mature formed dilated capillaries without anastomoses and cellular atypia consistent with capillary hemangioma. (Figure 4)

\section{DISCUSSION}

Hemangiomas are benign vascular tumors that can be classified as capillary or cavernous. The former consist of closely arranged capillary-like channels while the latter are composed of cavernous vascular spaces. ${ }^{4}$ Capillary hemangiomas typically occur in the skin, subcutaneous tissues, lips, liver and spleen or kidneys.' Cavernous hemangiomas often appear in the skin, mucosal surfaces and internal organs.' Histologically, capillary hemangiomas consist of closely arranged capillary like channels. ${ }^{1}$ This case of capillary hemangioma showed proliferation of well-circumscribed mature formed dilated capillaries.

The symptoms encountered by patients with hemangiomas of the ear include hearing loss, pulsating tinnitus, aural bleeding, facial nerve dysfunction, ear pain and recurrent ear infection and ear discharge..$^{2-5}$ Our patient also experienced on-and-off ear discharge, hearing loss and non-pulsatile tinnitus without facial nerve dysfunction. The types of hearing loss of patients with hemangioma of the ear can be conductive or mixed; ;,6-8 our patient had conductive hearing loss.

A diagnostic CT-scan of the temporal bone is important to localize the lesion and to determine bony erosion and involvement of the ossicular chain. ${ }^{7,9}$ Hemangiomas are enhancing soft tissue masses
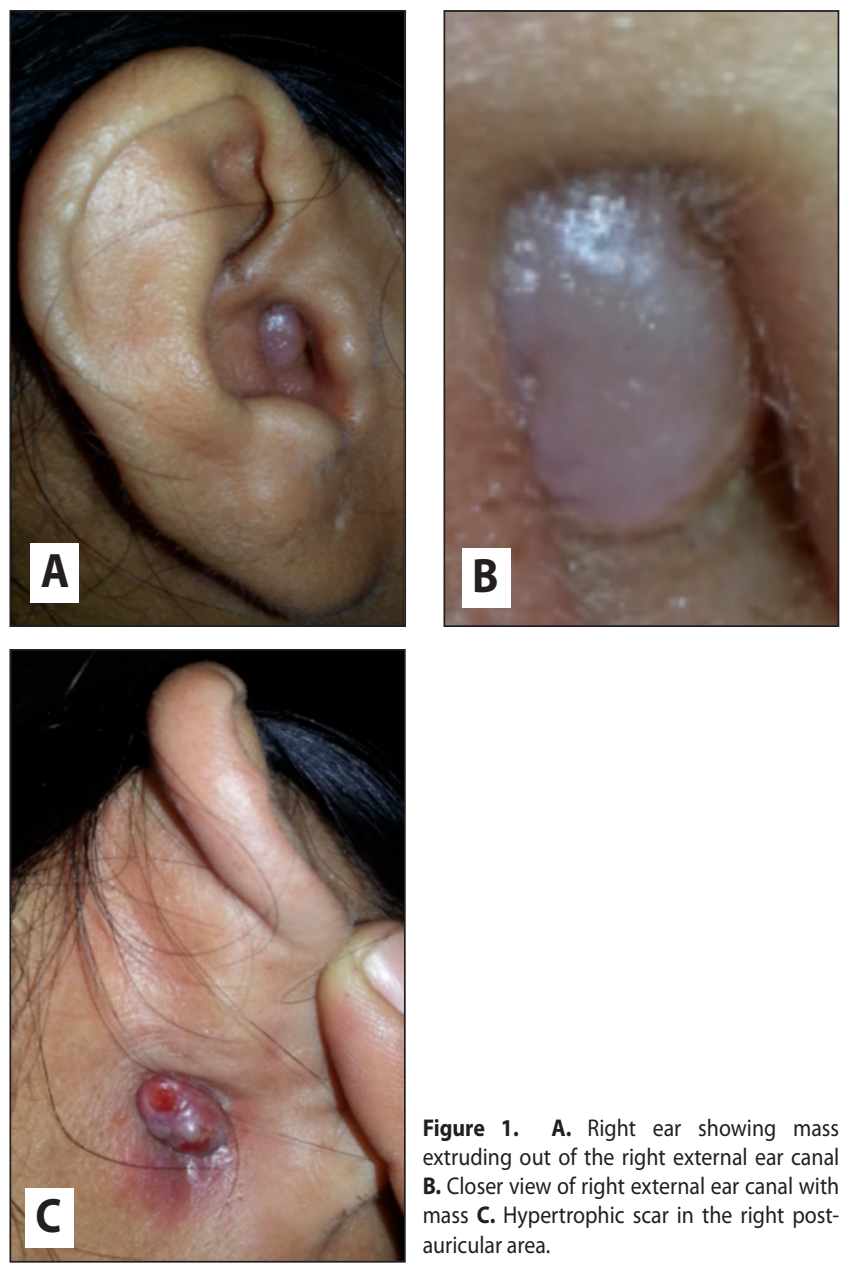

Figure 1. A. Right ear showing mass extruding out of the right external ear canal B. Closer view of right external ear canal with mass $\mathbf{C}$. Hypertrophic scar in the right postauricular area. 


\section{CASE REPORTS}
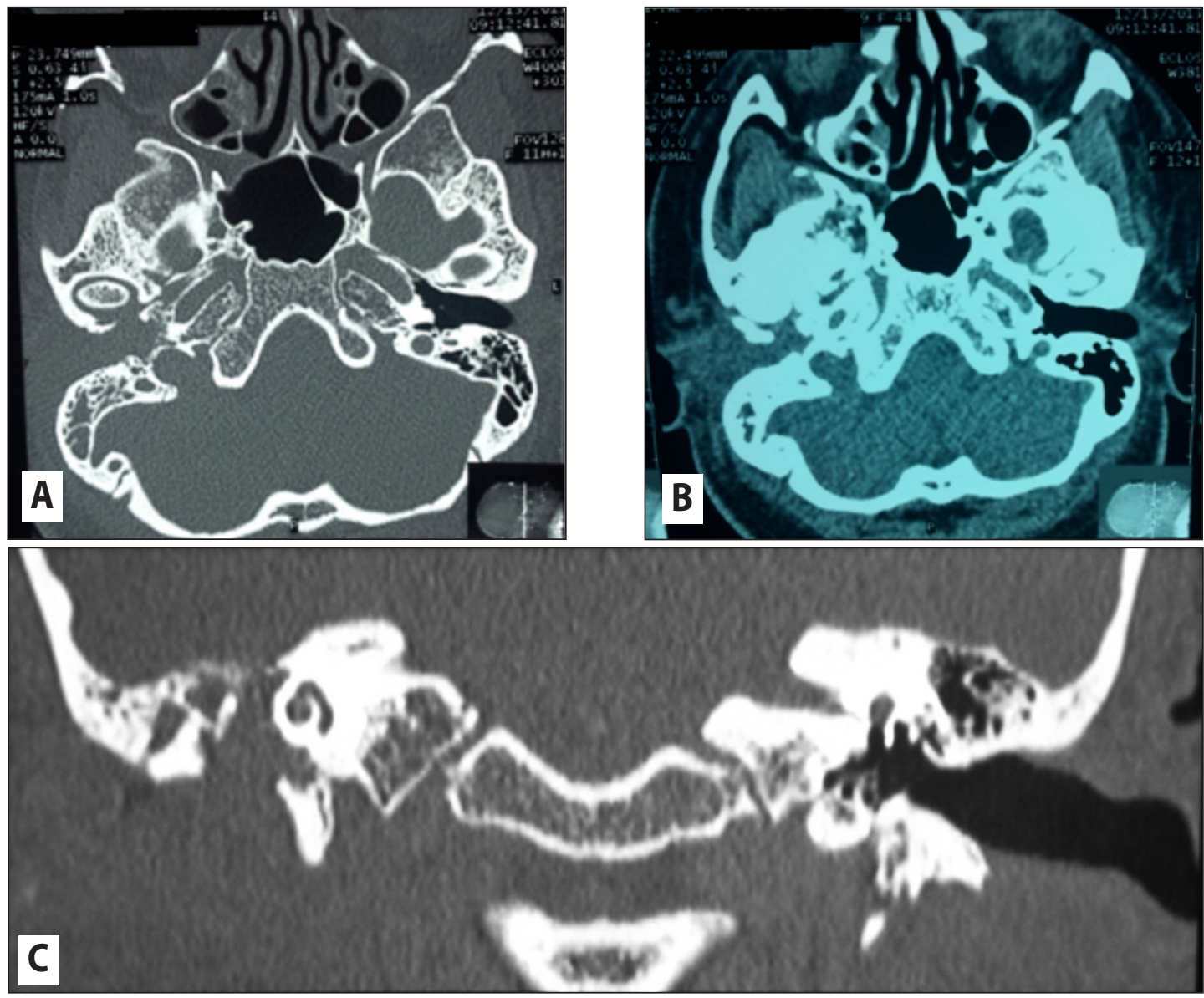

Figure 2. Temporal bone CT scan A. Axial section bone window, showing soft tissue density inside the external auditory canal and middle ear cavity with bone erosion of the anterior and posterior canal wall of the right ear. B. Axial section with contrast showing the same mass on the right ear which is heterogeneously enhancing C. Coronal section, bone window, showing erosion of the ossicles of the right ear.

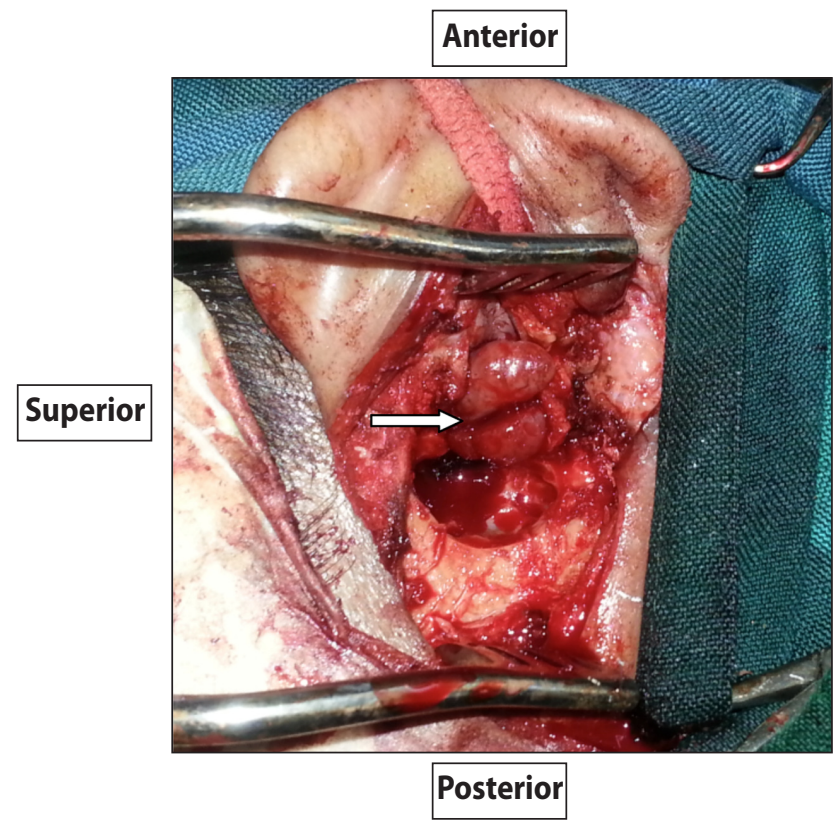

\section{Inferior}

Figure 3. Intra-operative view of capillary hemangioma occupying the middle ear and external auditory canal (arrow). 


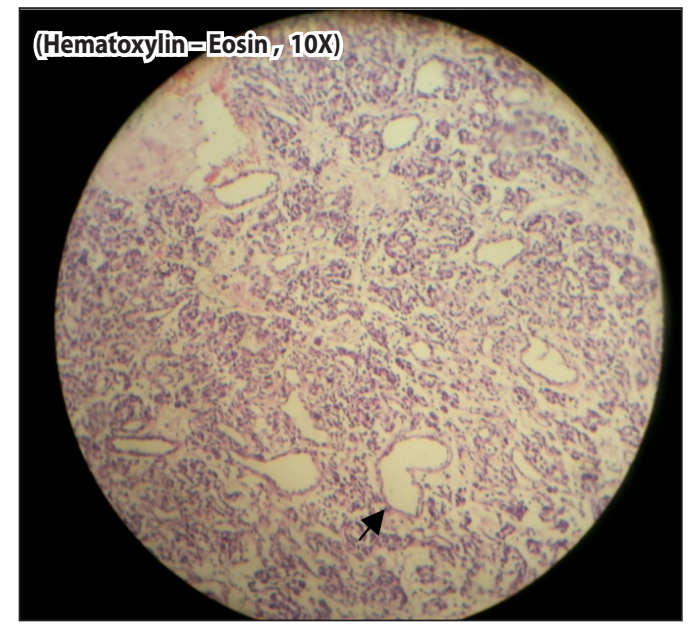

Figure 4. Histopathologic Low-power view (10X), Hematoxylin-Eosin stain, showing proliferation of well-circumscribed mature formed dilated capillaries (Arrow pointing at a mature formed dilated capillary).

as seen in the contrast CT-scan of our patient. ${ }^{4}$ Some cases reported in literature had no bony erosion or involvement of ossicular chain because they were either limited to the external auditory canal or early intervention was done..$^{1-10}$ Our patient had erosion of both the posterior and anterior auditory ear canal walls and all ossicles. On Magnetic Resonance Imaging (MRI), T1 weighted images show a lesion of moderate intensity and $\mathrm{T} 2$ weighted images show high intensity while the tumor is clearly enhanced. ${ }^{6}$ Angiography can be helpful in identifying feeding vessels for embolization prior to surgery. ${ }^{1,6}$ Hemangioma has been described as a vascular blush on arteriography. ${ }^{8}$ Our patient did not undergo pre-operative embolization due to financial constraints. However, we only sustained a total $900 \mathrm{ml}$ blood loss out of an allowable blood loss of 1,095 ml.

The surgical approach for capillary hemangioma of the ear depends on the involved area and extent. The procedure can be done transcanal if there is only external ear involvement or transmastoid with middle ear involvement. ${ }^{1,4,8-10}$ In our patient, a transmastoid approach was done for both middle ear and external auditory canal involvement. Compared to other cases where middle ear structures like the ossicles were not involved, ${ }^{1-10}$ our patient had erosion of the ossicles with ossification of the stapes footplate. This may have been caused by overlapping infection from manipulation and disease progression. Our case may suggest that such hemangiomas can become extensive and present with complications if no intervention is made.

Since there was a post-auricular sinus and a large mastoid cavity with multiple small bleeders from the bone bed despite aggressive hemostasis after excision of the hemangioma, surrounding granulation and fibrosis, we decided to completely obliterate the mastoid with abdominal fat and temporalis muscle and perform blind sac closure of the external auditory canal. The stapes footplate was also fixed, so hearing rehabilitation surgery as a second stage procedure would most likely not result in better hearing. Post-operatively, she was offered the use of a bone anchored hearing aid (BAHA) or a bone conducting hearing aid to address the conductive hearing loss on the right side.

The prognosis of capillary hemangioma is good and recurrence is rare after complete resection. ${ }^{14,6-8}$ However, it is associated with a high recurrence rate of $43.5 \%$ if resection is incomplete. ${ }^{2}$

Capillary hemangiomas of the middle ear are benign lesions of the temporal bone. However, left untreated, they may lead to disease progression and complications such as bone erosion, hearing loss, recurrent infection and bleeding. Surgery remains the ideal treatment, and prognosis is good, and the chance of recurrence is rare for complete resection.

\section{REFERENCES}

1. Martines F, Bentivegna D, Maira E, Marasa S, Ferrara S. Cavernous haemangioma of the external auditory canal: clinical case and review of the literature. Acta Otorhinolaryngol Ital. 2012 Feb; 32(1):54-57. PMID: 22500069; PMCID: PMC3324958.

2. Yang G, Li C, Chen X, Liu Y, Han D, Gao X, et al. Large capillary hemangioma of the temporal bone with a dural tail sign: A case report. Oncol Lett. 2014 Jul; 8(1):183-186. DOI: 10.3892 ol.2014.2143; PMID: 24959241; PMCID: PMC4063632.

3. Fierek O, Laskawi R, Kunze E. Large intraosseous hemangioma of the temporal bone in a child. Ann Otol Rhinol Laryngol. 2004 May; 113(5):394-8. DOI: 10.1177/000348940411300510; PMID: 15174768 .

4. Singh RK, Bhandary S, Tiwary A,Karki S. Capillary Hemangioma of Tympanic Cleft. Online J Health Allied Sci. 2008; 7(4):8. [cited 2014 Jul 28]. Available from: http://www.ojhas.org/issue28/20084-8.htm.

5. Hartwein JH, Raschke DT. Hemangioma of the middle ear. Laryngol Rhinol Otol (Stuttg). 1987 May; 66(5):280-2. PMID: 3613779.

6. Pistorio V, De Stefano A, Petrucci AG, Achilli V. Capillary haemangioma of the middle ear: a rare lesion difficult to evaluate. Acta Otorhinolaryngol ltal. 2011 Apr; 31(2):109-112. PMID: 22064794; PMCID: PMC3203740.

7. Alvarez-BuyllaBlanco M, Vazquez Barro JC, Lopez Amado M, Santiago Freijanes MP, Martinez Vidal J. Capillary hemangioma of middle ear a case report. Acta Otorrinolaringol Esp. 2011 JanFeb; 62 (1):74-76. DOI: 10.1016/j.otorri.2010.02.001; PMID: 20347430

8. Nouri H, Harkani A, Eloualildrissi M, Rochdi Y, Aderdour L, Oussehal A, Raji A, et al. Capillary hemangioma of the middle ear: one case report and review of the literature. Case Rep Otolaryngol.2012; 2012:305172. DOI: 10.1155/2012/305172; PMID: 22953107; PMCID: PMC3420627.

9. Neto JFL, Miura MS, Saleh C, de Andrade M, Assmann M. Hemangioma as mass of external ear canal. Intl Arch Otorhinolaryngol. 2007; 11(4): 498-500

10. Yasar H, Ozkul H, Somay A. A rare vascular tumor of the external auditory canal: the capillary hemangioma. Kulak Burun Bogaz Ihtis Derg. 2009 Jul-Aug; 19 (4):212-5. PMID: 19860637. 